\title{
Immature platelets in patients with Covid-19: association with disease severity
}

\author{
Amir Cohen ${ }^{1,2}$. Emanuel Harari ${ }^{1,2} \cdot$ Ella Yahud $^{1,2}$ (]) Michal Cipok ${ }^{2,3} \cdot$ Gabriel Bryk $^{2,3} \cdot$ Nili Karp Lador $^{2,4} \cdot$ Tal Mann $^{2,4}$. \\ Ami Mayo ${ }^{2,4}$. Eli I. Lev 1,2,5
}

Accepted: 29 August 2021 / Published online: 14 September 2021

@ The Author(s), under exclusive licence to Springer Science+Business Media, LLC, part of Springer Nature 2021

\begin{abstract}
Coronavirus disease 2019 (Covid-19) is associated with a high incidence of venous and arterial thromboembolic events. Currently, there are no clinical or laboratory markers that predict thrombotic risk. Circulating immature platelets are hyperreactive platelets, which are associated with arterial thrombotic events. The aim of this study was to assess whether the proportion of circulating immature platelets is associated with disease severity in Covid-19 patients. Patients admitted with Covid-19 disease were prospectively assessed. Immature platelet count (IPC) and immature platelet fraction (IPF) were measured at admission and at additional time points during the hospital course using the Sysmex XN-3000 auto-analyzer. A total of 136 consecutive patients with Covid-19 were recruited [mean age $60 \pm 19$ years, $49 \%$ woman, $56(41 \%)$ had mild-moderate disease and $80(59 \%)$ had severe disease at presentation]. The median IPF\% was higher in patients with severe compared to mild-moderate disease [5.8 (3.9-8.7) vs. $4.2(2.73-6.45)$, respectively, $\mathrm{p}=0.01]$. The maximal IPC value was also higher in patients with severe disease [15 (10.03-21.56), vs 10.9 (IQR 6.79-15.62), respectively, $p=0.001$ ]. Increased IPC was associated with increased length of hospital stay. Patients with severe Covid-19 have higher levels of IPF than patients with mild-moderate disease. IPF may serve as a prognostic marker for disease severity in Covid-19 patients.
\end{abstract}

Keywords Coronavirus disease $2019 \cdot$ Immature platelets · Platelet aggregation inhibitors · Reticulated platelets $\cdot$ SARS$\mathrm{CoV}-2$ infection $\cdot$ thrombosis

\section{Highlights}

- COVID-19 infection is associated with increased incidence thromboembolic events.

- We assessed the association between immature platelets and COVID-19 disease severity.

Eli I. Lev

elil@assuta.co.il

1 Cardiology Department, Assuta Ashdod Medical Center, Ashdod, Israel

2 The Faculty of Health Sciences, Ben-Gurion University, Be'ersheba, Israel

3 Laboratory Division, Assuta Ashdod Medical Center, Ashdod, Israel

4 Intensive Care Department, Assuta Ashdod Medical Center, Ashdod, Israel

5 Assuta Ashdod University Hospital, Ha-Refua St 7, 7747629 Ashdod, Israel
- Patients with severe disease had higher immature platelet fraction than those with mild-moderate disease.

- Increased immature platelet count predicted longer hospital stay.

- Immature platelet fraction may serve as a prognostic marker for COVID-19 disease severity.

- Anti-platelet drugs may be beneficial in patients with severe disease.

\section{Introduction}

From the outbreak of the Coronavirus disease pandemic in 2019 (Covid-19) the disease had a global effect on morbidity and mortality. Several case series have reported a range of clinical characteristics from mild respiratory infection to multi organ failure and death [1-3]. Patients with Covid-19, especially with severe presentation, have a high incidence of venous thromboembolic events (VTE) and pulmonary embolus (PE) as well as arterial thrombotic events. [4-7]. Disease 
severity and short-term mortality are associated with several hematologic abnormalities such as thrombocytopenia, lymphopenia, elevated D-dimer and fibrinogen degradation products [8-12].

Immature platelets released into the circulation from bone marrow by megakaryocytes, termed reticulated platelets (RPs), have been shown to be more pro-thrombotic and hyper-reactive than mature platelets and have high amount of dense granules which contain adenosine triphosphate (ATP), ionized calcium, and serotonin [13, 14]. RPs are known to be associated with high platelet turnover states, and have a greater predilection for thrombus formation [13-16].

Measuring the level of RPs is technically difficult and requires flow cytometry. Recently, an automated assayimmature platelet fraction (IPF) was introduced. It is performed in a simple and reproducible way by a hematology autoanalyzer (eg Sysmex XN-3000), which measures platelet count by optical fluorescence. There is a strong correlation between the levels of IPF and RPs in the blood [17].

We have recently shown that immature platelet indices such as IPF appear to be higher in patients with Covid-19 compared with patients with stable coronary artery disease, and even compared to patients with an acute coronary syndrome, known to have high levels of immature platelets [18]. Whether this increased level of immature platelets contributes to the high-rate of thromboembolic events in patients with Covid-19 and to disease severity is still unknown.

The aim of the current study was to evaluate whether the proportion of immature platelets in the circulation is associated with disease severity in patients with Covid-19.

\section{Methods}

Patients with Covid-19 disease, admitted to Assuta Ashdod Medical Center, Israel from March 2020 to October 2020 were prospectively recruited for study participation. SARSCoV2 infection was diagnosed by reverse transcription polymerase chain reaction (RT-PCR) test. Disease severity was defined according to the Covid-19 treatment guidelines [19].

\section{Mild illness}

Individuals who have any of the various signs and symptoms of Covid-19 (e.g., fever, cough, sore throat, malaise, headache, muscle pain, nausea, vomiting, diarrhea, loss of taste and smell) but who do not have shortness of breath, dyspnea, or abnormal chest imaging.

\section{Moderate illness}

Individuals who show evidence of lower respiratory disease during clinical assessment or imaging and who have an oxygen saturation $\left(\mathrm{SpO}_{2}\right) \geq 94 \%$ on room air at sea level.

\section{Severe illness}

Individuals who have $\mathrm{SpO}_{2}<94 \%$ on room air at sea level, a ratio of arterial partial pressure of oxygen to fraction of inspired oxygen $\left(\mathrm{PaO}_{2} / \mathrm{FiO}_{2}\right)<300 \mathrm{~mm} \mathrm{Hg}$, respiratory frequency $>30$ breaths/min, or lung infiltrates $>50 \%$.

\section{Critical illness}

Individuals who have respiratory failure, septic shock, and/ or multiple organ dysfunction.

Venous blood samples were drawn from each patient at 3 time points: (a) on admission to the hospital; (b) 3 days afterwards; (c) after one week of hospitalization; (d) on subsequent time point during index hospitalization. These time points were chosen in order to capture baseline IPF levels and follow its change during the hospitalization.

The level of IPF was determined as a part of complete blood cells count by an autoanalyzer Sysmex XN-3000 (Sysmex America Inc. Mundelein, Illinois, USA), which uses fluorescent dyes containing oxazine and ethylene glycol. This system discriminates between mature and immature platelets and reports the immature platelet fraction (IPF) as percentage and absolute number. IPC (immature platelet count) is calculated by multiplying IPF and total platelet count, representing the absolute count of immature platelets $\left(\times 10^{3} / \mu \mathrm{l}\right)$.

The normal reference range for IPF\% and IPC used in our laboratory (as defined by Sysmex) is $1.2-8.6 \%$ and $3.6-20.0 \times 10^{3} / \mu 1$, respectively. The analytical error in measuring IPF is $3.6 \%$. The association between severity of Covid-19 disease and IPF over time was evaluated.

The study was approved by the local investigational review board (ethics committee) of the Assuta Ashdod Hospital, Israel, and all subjects provided written informed consent.

\section{Statistical analysis}

Categorical variables were described as frequency rates and percentages, and continuous variables were described using median, and interquartile range (IQR) values. Continuous variables were compared using independent group t tests when the data were normally distributed; otherwise, the Mann-Whitney test was used. Statistical analyses were performed using GraphPad prism 9.1.0. Multivariant analyses 
was performed using JMP software version 15.1.0—SAS Institute Inc, NC USA.

For hospitalization length Fit least square Model was used and for in-hospital mortality a logarithmic regression was used. For comparisons, a 2 -sided $\alpha$ of less than 0.05 was considered statistically significant.

\section{Results}

\section{Baseline characteristics}

A total of 136 consecutive patients were included in this study. Among them, $56(41 \%)$ had mild or moderate disease and $80(59 \%)$ had severe disease at presentation. Eight patients (5.9\%) started with mild disease and deteriorated to severe disease. Mean length of hospitalization was $9.1 \pm 5.5$ days. Among patients who were hospitalized $6(4.5 \%)$ required mechanical ventilation during their hospital stay; $76(56 \%)$ were treated with dexamethasone and 51 (37.5\%) received plasma during their admission. Ninety-nine patients $(72.8 \%)$ were treated with low molecular weight heparin during their hospital stay [73 (91.3\%) with severe disease and 26 (46.4\%) with mild or moderate disease]. Overall, in-hospital mortality rate was $11.8 \%$. Patients with mild and moderate disease were younger than those with severe disease (mean age $60 \pm 19$ vs $69 \pm 14$, respectively); $29(52 \%)$ with mild or moderate disease and $38(48 \%)$ with severe disease were women, and $6(11 \%)$ with mild or moderate disease and $16(20 \%)$ with severe disease had concurrent cardiovascular disease. The baseline characteristics of the patients are presented in Table 1.

\section{Immature platelet indices and disease severity}

The median of IPF\% was higher in patients with severe Covid-19 compared to patients with mild or moderate disease [5.8 (IQR 3.9-8.7) vs. 4.2 (IQR 2.73-6.45), respectively, $\mathrm{p}=0.01$, Table 2, Fig. 1]. The median of IPF absolute number was also significantly higher in patients with severe disease compared to patients with mild or moderate disease [5.1 (IQR 3.65-7.35) vs. 4.2 (IQR 2.85-6.1), respectively, $\mathrm{p}<0.0001$, Table 2, Fig. 1]. The maximal IPC value was also significantly higher in patients with severe disease compared to patients with mild or moderate disease [15 (IQR 10.03-21.56), vs 10.9 (IQR 6.79-15.62) respectively, $\mathrm{p}=0.001$, Table 2, Fig. 1].

\section{Platelet's indices, length of hospitalization and in hospital mortality}

Multivariable models were used to examine the relationship between individual baseline characteristics including IPF levels and mortality/length of hospital stay. Advanced age was found to have the strongest impact on mortality based on logarithmic regression model (Table 3). No significant association was found between IPF or IPC and in hospital mortality. Maximal IPC was found to be associated with the length of hospitalization as was shown using least squares means model $(\log$ worth $1.338, p=0.045$, Table 4$)$.

\section{Discussion}

To our knowledge, the current study is the first to examine the association between immature platelet indices and Covid-19 disease severity. In this prospective study, we found that immature platelet indices were higher in patients with severe disease than with mild-moderate disease. These findings imply that immature platelets may have a role in Covid-19 disease progression and severity.

Patients with Covid-19 are prone to develop thrombotic events, including venous thromboembolic events, which are related to hypercoagulability states $[19,20]$, and acute arterial events, which are primarily platelet mediated [21-23]. The latter may be related to states of enhanced platelet turnover, similar to the increased turnover reported in patients with acute coronary syndrome [24-26]. In patients with acute coronary syndrome elevated levels of immature platelets have been associated with increased risk for arterial thrombotic events and poor clinical outcomes [27-29].

SARS-CoV2 infection promotes endothelial dysfunction in the pulmonary vascular bed and possibly other vessels, resulting in microvascular thrombosis [30]. This could explain the increased D-dimer associated with severe Covid19 [11]. When combined with enhanced platelet turnover and reactivity, the high risk for thrombotic events may be explained.

Viruses can directly cause thrombocytopenia via megakaryocytes apoptosis or destruction of platelets during viremia. Reactive thrombopoiesis may ensue thereafter. SARS-CoV2, similar to other viruses, such as H1N1 influenza infection, can cause severe systemic inflammatory response, accompanied by increased platelet consumption and eventually increased thrombosis events due to enhanced thrombopoiesis [31, 32]. Zhang et al. recently showed that SARS-CoV-2 directly activates platelets via binding of to ACE2, which may participate in thrombus formation and inflammatory responses in Covid-19 patients [33]. Thus, both a direct virus-platelet interaction, and a systemic inflammatory response to the virus with resultant enhanced thrombopoiesis may participate in the pathogenesis of thrombotic events in patients with Covid-19 disease.

Our study may have clinical implication for anti-thrombotic treatment in patients with severe Covid-19 disease. Anticoagulation is routinely used to prevent venous 
Table 1 Demographic and clinical characteristics of patients with mild-moderate vs severe COVID-19 disease

\begin{tabular}{|c|c|c|c|}
\hline & $\begin{array}{l}\text { Mild- Moderate COVID- } \\
19 n=56\end{array}$ & $\begin{array}{l}\text { Severe COVID-19 } \\
\mathrm{n}=80\end{array}$ & P-Value \\
\hline \multicolumn{4}{|l|}{ Demographic characteristics } \\
\hline Age, median (IQR), year & $60 \pm 19$ & $69 \pm 14$ & \\
\hline Women, $\mathrm{n}(\%)$ & $29(52)$ & $38(48)$ & 0.58 \\
\hline Weight, kg & $81.3 \pm 17$ & $85 \pm 16$ & \\
\hline Smoker, $\mathrm{n}(\%)$ & $3(5.4)$ & $5(6)$ & 0.85 \\
\hline \multicolumn{4}{|l|}{ Past medical history } \\
\hline Diabetes, n(\%) & $19(34)$ & $36(45)$ & 0.23 \\
\hline Hypertension, $\mathrm{n}(\%)$ & $28(50)$ & $41(51)$ & 0.95 \\
\hline Dyslipidemia, n(\%) & $16(29)$ & $32(40)$ & 0.2 \\
\hline $\mathrm{CAD}, \mathrm{n}(\%)$ & $6(11)$ & $16(20)$ & 0.15 \\
\hline CHF, n(\%) & $3(5.5)$ & $8(10)$ & 0.35 \\
\hline CRF, $\mathrm{n}(\%)$ & $6(11)$ & $8(10)$ & 0.88 \\
\hline Atrial fibrillation, $\mathrm{n}(\%)$ & $9(16)$ & $8(10)$ & 0.28 \\
\hline Dialysis, $\mathrm{n}(\%)$ & $3(5.5)$ & $2(2.5)$ & 0.38 \\
\hline CABG, $\mathrm{n}(\%)$ & 0 & $2(2.5)$ & - \\
\hline COPD, n(\%) & 0 & $10(12.5)$ & - \\
\hline Asthma, $\mathrm{n}(\%)$ & $1(1.8)$ & $5(6)$ & 0.22 \\
\hline CVA, n(\%) & $4(7)$ & $8(10)$ & 0.58 \\
\hline \multicolumn{4}{|l|}{ Drugs } \\
\hline Diabetes drugs, $\mathrm{n}(\%)$ & $9(16)$ & $20(25)$ & 0.22 \\
\hline Insulin & $5(9)$ & $34(42.5)$ & 0.00003 \\
\hline ACE/ARB,n(\%) & $18(32)$ & $30(38)$ & 0.56 \\
\hline Beta blocker, n(\%) & $11(20)$ & $30(38)$ & 0.03 \\
\hline $\mathrm{CCB}, \mathrm{n}(\%)$ & $11(20)$ & $10(12.5)$ & 0.25 \\
\hline Statin, $\mathrm{n}(\%)$ & $16(29)$ & $24(30)$ & 0.9 \\
\hline Aspirin, $\mathrm{n}(\%)$ & $12(22)$ & $22(27.5)$ & 0.45 \\
\hline P2Y2 Inhibitor, n(\%) & $6(11)$ & $4(5)$ & 0.95 \\
\hline NOAC, $\mathrm{n}(\%)$ & $7(12.5)$ & $5(6)$ & 0.2 \\
\hline Diuretics, n(\%) & $8(14)$ & $21(26)$ & 0.1 \\
\hline PPI, n(\%) & $24(43)$ & $65(81)$ & $<0.00001$ \\
\hline \multicolumn{4}{|c|}{ Treatment during hospital stay } \\
\hline Plaqunil, n(\%) & $10(18)$ & $16(20)$ & 0.8 \\
\hline Remdesivir, n(\%) & $5(9)$ & $38(47)$ & $<0.00001$ \\
\hline Mebeverine, $\mathrm{n}(\%)$ & $1(1.8)$ & $1(1.25)$ & 0.8 \\
\hline Lopinavir/ritonavir, n(\%) & 0 & $11(14)$ & - \\
\hline Clexane, $\mathrm{n}(\%)$ & $25(45)$ & $74(93)$ & $<0.00001$ \\
\hline VIT D, n(\%) & $13(23)$ & $40(50)$ & 0.002 \\
\hline Plasma, n(\%) & $7(12.5)$ & $44(55)$ & $<0.00001$ \\
\hline Steroids, n(\%) & $15(27)$ & $61(76)$ & $<0.00001$ \\
\hline Antibiotics, n(\%) & $7(12.4)$ & $32(40)$ & 0.001 \\
\hline
\end{tabular}

Dyslipidemia defined as statin use; $C R F$ chronic renal failure: GFR $<60 \mathrm{ml} / \mathrm{min} / 1.73 \mathrm{~m} 2 ; C A D$ coronary artery disease: diagnosed by coronary angiography or cardiac computer tomography; $C H F$ congestive heart failure: recent hospitalization due to $\mathrm{CHF}$ in the presence of reduced ejection fraction (EF) or abnormal diastolic dysfunction; $C A B G$ coronary artery bypass grafting; $C O P D$ chronic obstructive pulmonary disease; $C V A$ cerebrovascular accident; $A C E / A R B$ angiotensin-converting enzyme inhibitors/angiotensin II receptor blockers; $C C B$ calcium channel blockers; NOAC novel oral anticoagulants; PPI proton-pump inhibitors

thromboembolism in patients with severe Covid-19. It remains unknown whether antiplatelet medications should be part of the therapeutic regimen as well, but the high levels of IPF in patients with severe disease suggest that anti-platelet drugs may have a role in this group of patients. In addition, immature platelet indices may have a role in 
Table 2 Immature platelets indices in according to Covid19 disease severity

\begin{tabular}{lcll}
\hline & Mild-Moderate Covid-19 $\mathrm{n}=56$ & SEVERE Covid-19 $\mathrm{n}=80$ & $\mathrm{P}$ Value \\
\hline IPF $(\%)$ & $4.2(2.73-6.45)$ & $5.8(3.9-8.7)$ & $\mathrm{P}=0.01$ \\
IPF $\left(\times 10^{3} / \mu \mathrm{l}\right)$ & $4.2(2.85-6.1)$ & $5.1(3.65-7.35)$ & $\mathrm{P}<0.0001$ \\
Max. IPC $\left(\times 10^{3} / \mu \mathrm{l}\right)$ & $10.9(\mathrm{IQR} 6.79-15.62)$ & $15($ IQR 10.03-21.56) & $\mathrm{P}=0.001$ \\
\hline
\end{tabular}

$\mathrm{p}$ values were calculated using Mann-Whitney test
Fig. 1 Association between platelets indices and Covid-19 severity

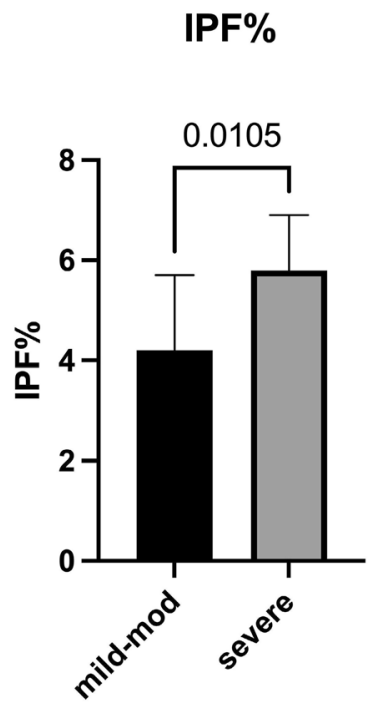

Table 3 Factors associated with mortality in logarithmic analysis

\begin{tabular}{lll}
\hline Variable & LogWorth & p-value \\
\hline Age & 1.489 & 0.034 \\
Body weight & 1.123 & 0.075 \\
Hemodialysis & 1.053 & 0.089 \\
IHD & 0.928 & 0.118 \\
Max IPC & 0.479 & 0.321 \\
Diabetes mellitus & 0.289 & 0.515 \\
\hline
\end{tabular}

$I H D$ ischemic heart disease, $I P C$ immature platelet count

risk stratification of patients with Covid-19, as maximal IPC was associated with the length of hospital stay-a marker of disease severity in this group of patients.

There are several limitations in our study. First it is a single center, non-randomized observational trial with a relatively small sample size. Second, there were differences in treatment protocols between the two groups. Third, about $6 \%$ of the patients changed their disease severity status during hospitalization.
Absolute IPF Number

Max IPC
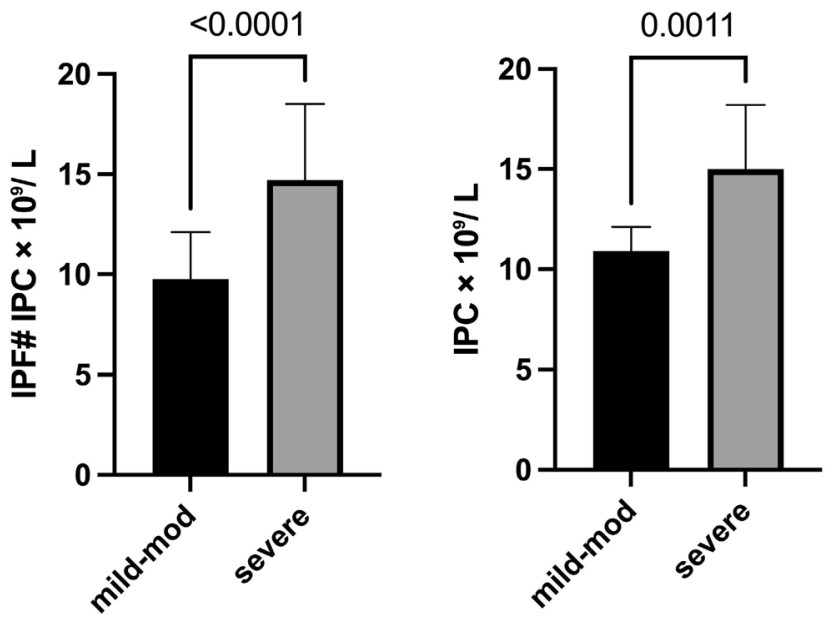

Table 4 Factors associated with length of hospitalization

\begin{tabular}{lll}
\hline Source & LogWorth & p-value \\
\hline Max IPC & 1.338 & 0.045 \\
Body weight & 0.947 & 0.112 \\
Hyperlipidemia & 0.875 & 0.133 \\
Hemodialysis & 0.852 & 0.140 \\
IHD & 0.680 & 0.208 \\
Age & 0.677 & 0.210 \\
Hypothyroidism & 0.674 & 0.211 \\
Smoker & 0.625 & 0.236 \\
CHF & 0.546 & 0.284 \\
Max IPF\% & 0.527 & 0.296 \\
Hypertension & 0.386 & 0.411 \\
Diabetes mellitus & 0.285 & 0.519 \\
\hline
\end{tabular}

$I H D$ ischemic heart disease, $C H F$ congestive heart failure, $I P F$ immature platelet fraction, $I P C$ immature platelet count

\section{Conclusions}

Patients with severe Covid-19 disease appear to have enhanced platelet turnover, reflected by high level of immature platelets compared to patients with mild or moderate Covid-19 disease. This finding may have clinical 
implications for risk stratification and anti-thrombotic treatment in patients with Covid-19.

Acknowledgements We would like to thank the staff of the Laboratory Division and Intensive Care Unit.

Author contributions AC and EY prepared the manuscript, including tables and figures, in consultation with EIL and AM and assisted by MC, GB, NKL, TM, EH performed the statistical analysis and created the draft figures. All the authors critically revised the manuscript and approved the final version to be published.

\section{Declarations}

Conflict of interest There are no relevant financial or non-financial competing interests to report.

\section{References}

1. Chen N, Zhou M, Dong X, Qu J, Gong F, Han Y, Qiu Y, Wang J, Liu Y, Wei Y et al (2020) Epidemiological and clinical characteristics of 99 cases of 2019 novel coronavirus pneumonia in Wuhan, China: a descriptive study. Lancet 395(10223):507-513

2. Huang C, Wang Y, Li X, Ren L, Zhao J, Hu Y, Zhang L, Fan G, Xu J, Gu X et al (2020) Clinical features of patients infected with 2019 novel coronavirus in Wuhan. China Lancet 395(10223):497-506

3. Wang D, Hu B, Hu C, Zhu F, Liu X, Zhang J, Wang B, Xiang $\mathrm{H}$, Cheng Z, Xiong Y et al (2020) Clinical characteristics of 138 hospitalized patients with 2019 novel coronavirus-infected pneumonia in Wuhan China. JAMA 323(11):1061-1069

4. Boonyawat $\mathrm{K}$, Chantrathammachart $\mathrm{P}$, Numthavaj $\mathrm{P}$, Nanthatanti N, Phusanti S, Phuphuakrat A, Niparuck P, Angchaisuksiri P (2020) Incidence of thromboembolism in patients with Covid19: a systematic review and meta-analysis. Thromb J 18(1):34

5. Zhang L, Feng X, Zhang D, Jiang C, Mei H, Wang J, Zhang C, Li $\mathrm{H}$, Xia X, Kong S et al (2020) Deep vein thrombosis in hospitalized patients with Covid-19 in Wuhan, China: prevalence, risk factors, and outcome. Circulation 142(2):114-128

6. Dubois-Silva Á, Barbagelata-López C, Mena Á, Piñeiro-Parga P, Llinares-García D, Freire-Castro S (2020) Pulmonary embolism and screening for concomitant proximal deep vein thrombosis in noncritically ill hospitalized patients with coronavirus disease 2019. Intern Emerg Med 15(5):865-870

7. Mestre-Gómez B, Lorente-Ramos RM, Rogado J, Franco-Moreno A, Obispo B, Salazar-Chiriboga D, Saez-Vaquero T, TorresMacho J, Abad-Motos A, Cortina-Camarero C, Infanta Leonor Thrombosis Research Group (2021) Incidence of pulmonary embolism in non-critically ill Covid-19 patients. Predicting factors for a challenging diagnosis. J Thromb Thrombolysis 51(1):40-46

8. Shang W, Dong J, Ren Y, Tian M, Li W, Hu J, Li Y (2020) The value of clinical parameters in predicting the severity of Covid-19. J Med Virol 92(10):2188-2192

9. Chan JF, Yuan S, Kok KH, To KK, Chu H, Yang J, Xing F, Liu J, Yip CC, Poon RW et al (2020) A familial cluster of pneumonia associated with the 2019 novel coronavirus indicating person-to-person transmission: a study of a family cluster. Lancet 395(10223):514-523

10. Lippi G, Plebani M, Henry BM (2020) Thrombocytopenia is associated with severe coronavirus disease 2019 (Covid-19) infections: a meta-analysis. Clin Chim Acta 506:145-148
11. Zhou F, Yu T, Du R, Fan G, Liu Y, Liu Z, Xiang J, Wang Y, Song $\mathrm{B}, \mathrm{Gu} \mathrm{X}$ et al (2020) Clinical course and risk factors for mortality of adult inpatients with Covid-19 in Wuhan, China: a retrospective cohort study. Lancet 395(10229): 1054-1062

12. Tang N, Li D, Wang X, Sun Z (2020) Abnormal coagulation parameters are associated with poor prognosis in patients with novel coronavirus pneumonia. J Thromb Haemost 18(4):844-847

13. Lev EI (2016) Immature platelets: clinical relevance and research perspectives. Circulation 134(14):987-988

14. Hille L, Lenz M, Vlachos A, Grüning B, Hein L, Neumann FJ, Nührenberg TG, Trenk D (2020) Ultrastructural, transcriptional, and functional differences between human reticulated and nonreticulated platelets. J Thromb Haemost 18(8):2034-2046

15. Bernlochner I, Goedel A, Plischke C, Schüpke S, Haller B, Schulz C, Mayer K, Morath T, Braun S, Schunkert H et al (2015) Impact of immature platelets on platelet response to ticagrelor and prasugrel in patients with acute coronary syndrome. Eur Heart J 36(45):3202-3210

16. Freynhofer MK, Gruber SC, Grove EL, Weiss TW, Wojta J, Huber K (2015) Antiplatelet drugs in patients with enhanced platelet turnover: biomarkers versus platelet function testing. Thromb Haemost 114(3):459-468

17. Pons I, Monteagudo M, Lucchetti G, Muñoz L, Perea G, Colomina I, Guiu J, Obiols J (2010) Correlation between immature platelet fraction and reticulated platelets Usefulness in the etiology diagnosis of thrombocytopenia. Eur J Haematol 85(2):158-163

18. Cohen A, Harari E, Cipok M, Laish-Farkash A, Bryk G, Yahud E, Sela Y, Lador NK, Mann T, Mayo A et al (2021) Immature platelets in patients hospitalized with Covid-19. J Thromb Thrombolysis 51(3):608-616

19. Lenz, Maximilian, et al. Covid-19 Treatment guidelines panel. Coronavirus Disease 2019 (Covid-19) Treatment Guidelines. National Institutes of Health

20. Spiezia L, Boscolo A, Poletto F, Cerruti L, Tiberio I, Campello E, Navalesi P, Simioni P (2020) Covid-19-related severe hypercoagulability in patients admitted to intensive care unit for acute respiratory failure. Thromb Haemost 120(6):998-1000

21. Bangalore S, Sharma A, Slotwiner A, Yatskar L, Harari R, Shah B, Ibrahim H, Friedman GH, Thompson C, Alviar CL et al (2020) ST-segment elevation in patients with Covid-19-a case series. N Engl J Med 382(25):2478-2480

22. Oxley TJ, Mocco J, Majidi S, Kellner CP, Shoirah H, Singh IP, De Leacy RA, Shigematsu T, Ladner TR, Yaeger KA et al (2020) Large-vessel stroke as a presenting feature of Covid-19 in the young. N Engl J Med 382(20):e60

23. Stefanini GG, Montorfano M, Trabattoni D, Andreini D, Ferrante G, Ancona M, Metra M, Curello S, Maffeo D, Pero G et al (2020) ST-elevation myocardial infarction in patients with Covid-19: clinical and angiographic outcomes. Circulation 141(25):2113-2116

24. Cesari F, Marcucci R, Gori AM, Caporale R, Fanelli A, Casola G, Balzi D, Barchielli A, Valente S, Giglioli C et al (2013) Reticulated platelets predict cardiovascular death in acute coronary syndrome patients. Insights from the AMI-Florence 2 Study. Thromb Haemost 109(5):846-853

25. Martin JF, Kristensen SD, Mathur A, Grove EL, Choudry FA (2012) The causal role of megakaryocyte-platelet hyperactivity in acute coronary syndromes. Nat Rev Cardiol 9(11):658-670

26. Grove EL, Hvas AM, Mortensen SB, Larsen SB, Kristensen SD (2011) Effect of platelet turnover on whole blood platelet aggregation in patients with coronary artery disease. J Thromb Haemost 9(1):185-191

27. López-Jiménez RA, Martín-Herrero F, González-Porras JR, Sánchez-Barba M, Martín-Luengo C, Pabón-Osuna P (2013) Immature platelet fraction: a new prognostic marker in acute coronary syndrome. Rev Esp Cardiol 66(2):147-148

28. Gonzalez-Porras JR, Martin-Herrero F, Gonzalez-Lopez TJ, Olazabal J, Diez-Campelo M, Pabon P, Alberca I, San Miguel JF 
(2010) The role of immature platelet fraction in acute coronary syndrome. Thromb Haemost 103(1):247-249

29. Grove EL, Hvas AM, Kristensen SD (2009) Immature platelets in patients with acute coronary syndromes. Thromb Haemost 101(1):151-156

30. Ackermann M, Verleden SE, Kuehnel M, Haverich A, Welte T, Laenger F, Vanstapel A, Werlein C, Stark H, Tzankov A et al (2020) Pulmonary vascular endothelialitis, thrombosis, and angiogenesis in Covid-19. N Engl J Med 383(2):120-128

31. Bunce PE, High SM, Nadjafi M, Stanley K, Liles WC, Christian MD (2011) Pandemic H1N1 influenza infection and vascular thrombosis. Clin Infect Dis 52(2):e14-e17

32. Rondina MT, Brewster B, Grissom CK, Zimmerman GA, Kastendieck DH, Harris ES, Weyrich AS (2012) In vivo platelet activation in critically ill patients with primary 2009 influenza A(H1N1). Chest 141(6):1490-1495

33. Zhang S, Liu Y, Wang X, Yang L, Li H, Wang Y, Liu M, Zhao X, Xie Y, Yang Y et al (2020) SARS-CoV-2 binds platelet ACE2 to enhance thrombosis in Covid-19. J Hematol Oncol 13(1):120

Publisher's Note Springer Nature remains neutral with regard to jurisdictional claims in published maps and institutional affiliations. 